\title{
Measurement and modeling of concentrated runoff in grassed waterways
}

\author{
P. Fiener ${ }^{\mathrm{a}}, \mathrm{K}$. Auerswald ${ }^{\mathrm{b}, *}$ \\ ${ }^{a}$ Department of Geography, Chair of Hydrogeography and Climatology, University of Cologne, \\ Albertus-Magnus-Platz, D-50923 Köln, Germany \\ ${ }^{\mathrm{b}}$ Department of Plant Sciences, Chair of Grassland Science, Technische Universiät München, Am Hochanger 1, \\ D-85350 Freising-Weihenstephan, Germany
}

\begin{abstract}
Grassed waterways (GWWs) are a common measure to drain surface runoff from fields without gullying along the drainageway (thalweg). Moreover, they have a great potential to reduce runoff volume and peak discharge rate, especially if they are located in relatively small watersheds typical for many small patterned landscapes in Europe. Due to the flow characteristics in a GWW, an area of shallow sheet flow on the side-slopes and another of concentrated flow along the thalweg can be identified. The runoff control on the side-slopes is comparable to that of vegetative filter strips, which was intensively investigated in many studies. Our objectives were to use experimental field data, modeling and a sensitivity analysis to evaluate the parameters (morphology, soil, vegetation, water input) dominating the concentrated runoff along the thalweg of a GWW, and thus to optimize GWW layout. The experimental data were derived by pumping concentrated inflow to the upstream end of two GWWs (290 and $370 \mathrm{~m}$ long). The used model is simulating infiltration according to the Philip's [Adv. Hydrosci. 5 (1969) 215 ] equation and routing the runoff with a kinematic wave approximation. The experiment showed a great difference in runoff control between the two tested GWWs, e.g. one reduced runoff volume by $90 \%$ the other by $49 \%$. The model agreed well with the experimental data. From the sensitivity analysis of the model parameters, it appeared that the main reason for the difference in runoff characteristics was the flat-bottomed compared to more or less v-shaped cross-section of the thalweg. Differences in hydraulic roughness between the tested GWWs were small, but in general hydraulic roughness is a sensitive parameter in runoff control of a GWW, because in case of grass submergence or high runoff velocities grass is bent to the ground, and hence the hydraulic roughness drops drastically. Soil conditions are only prominent if higher saturated conductivities were assumed than measured at the test site. For colluvial soils typically found where GWWs are established similar efficiencies in runoff control can be expected for similar inflow hydrographs.

In general, a high potential of GWWs to reduce runoff volume and peak discharge could be verified within the examined scope of site conditions.
\end{abstract}

Keywords: Grassed waterway; Runoff control; Soil conservation; Modeling

\footnotetext{
* Corresponding author. Tel.: +49-8161-713965; fax: +49-8161-713243.

E-mail address: auerswald@wzw.tum.de (K. Auerswald).
} 


\section{Introduction}

In areas of extensive farming non-point source pollution by water-soluble and sediment bound pollutants is a major problem. Moreover, damages of infrastructure and private properties by muddy floods coming from agricultural land arise in areas of dense population (Verstraeten and Poesen, 1999). To treat these problems grass has been used extensively to control runoff and sediment delivery from agricultural land. Lots of studies have been carried out, dealing with the effects of grass or vegetative filter strips (VFS) located at the downstream end of fields or along surface water bodies (Norris, 1993). Most of these studies were plot experiments evaluating the sediment trapping efficiency, the runoff reduction and the trapping of pollutants in VFS (Barfield et al., 1998; Chaubey et al., 1994, 1995; Schmitt et al., 1999; Zillgens, 2001), few were field (Schauder and Auerswald, 1992) or flume experiments (Jin and Römkens, 2001). Results of the reduction of runoff ranged from 6\% (Chaubey et al., 1994) to $89 \%$ (Schmitt et al., 1999) and of sediment delivery from 15\% (Chaubey et al., 1994) to 99\% (Schmitt et al., 1999). From the studies and their highly variable results, it can be concluded that the sediment trapping efficiency and the runoff reduction of a VFS depend on: inflow characteristics (volume, depth, rate, shallow or concentrated flow), precipitation characteristics (duration and intensity), sediment characteristics (concentration and grain size distribution), grass characteristics (length, density and species composition), terrain characteristics (slope, length and width) and soil type (infiltration capacity and surface roughness).

Beside these experimental studies, there exist a few mathematical models of runoff reduction and sediment trapping in VFS (Deletic, 2001; Hayes et al., 1984; Munoz-Carpena et al., 1993, 1999; Overcash et al., 1981; Tollner et al., 1976, 1977). The more recent models (Deletic, 2001; Munoz-Carpena et al., 1993, 1999) consist of two sub models, one computing the infiltration according to the Green \& Ampt equation and routing the surface runoff with a kinematic wave approximation, and a second simulating sediment transport and particle deposition.

The efficacy of grassed waterways (GWWs) in reducing runoff and sediment load has been investigated only in a few studies (Briggs et al., 1999; Chow et al., 1999; Fiener and Auerswald, 2003b; Hjelmfelt and Wang, 1997). Briggs et al. (1999), for example, found a runoff reduction of $47 \%$ and a severe herbicide reduction in a GWW in a laboratory experiment, but their experimental setup was similar to that of many VFS experiments. In a landscape experiment where potato production with commonly up-and-down slope cultivation was compared to terraces/GWW systems, the average runoff was reduced by $86 \%$ and the average sediment delivery by $95 \%$ establishing the terraces/GWW systems (Chow et al., 1999). Hjelmfelt and Wang (1997) computed that on average a total runoff reduction of $5 \%$ and a maximum discharge reduction of $54 \%$ could be expected from a $600 \mathrm{~m}$ long and $10 \mathrm{~m}$ wide GWW within a 34 ha watershed. Other watershed models (e.g. H-KIN, Schröder, 2000) take a GWW into account as an area of high infiltration capacity, which largely effects infiltration after the end of a rain event (afterflow infiltration) due to the prolonged travel time. These models commonly assume a uniform flow on the total or a previously defined width of a GWW.

However to understand in more detail, the effects of a GWW on runoff and sediment delivery reduction it is necessary to focus on its terrain characteristics. (1) A GWW is commonly much longer than a VFS. Hence, the interactions between duration of rain, watershed characteristics and duration of runoff in a watershed are clearly different from that of a VFS. (2) Compared to a VFS the terrain of a GWW can be divided into two parts: The side-slopes, where shallow sheet flow enters the GWW from the neighboring fields. This area should behave similar as any VFS, with the only difference that it is closer to the source of runoff generation and hence it is more likely that runoff enters the grass as shallow sheet flow. The second area is the area of concentrated flow along the channel base (thalweg) of the GWW. The influence of this area, which is of major importance during afterflow infiltration or if a GWW is used as outlet of a terrace or ditch system, depends on the inflow rate, the grass characteristics, the cross-section and length of a GWW.

From the existing studies, it can be expected that a GWW should be more efficient, the smaller the contributing fields and the runoff events are. A high 
efficiency should result for the small-pattered European landscape and moderate rainfall. Due to the limitations of existing knowledge and the difficulties in applying the results of the VFS studies to GWWs, an investigation of the effects of GWWs on runoff and soil delivery from small watersheds was undertaken within the Munich Research Alliance (FAM). A longterm landscape experiment was carried out in two GWWs between January 1994 and December 2000. The results of these experiments (Fiener and Auerswald, 2003b) show a great difference between the two GWWs, one reduced sediment delivery and runoff by 77 and 10\%, respectively, the other by 97 and $90 \%$, respectively. For a further understanding of these differences, especially the differences in runoff reduction, we carried out this study, with the major objective to determine the influence of the area of concentrated flow in a GWW on its runoff characteristics. Therefore, (1) the results of a controlled landscape experiment where concentrated inflow was pumped to the upstream end of the two GWWs was analyzed, (2) a mathematical model simulating concentrated runoff in a GWW was developed and validated with the experimental data, and (3) a sensitivity analysis of the modeled parameters was carried out.

\section{Material and methods}

\subsection{Test site}

The GWWs were located at the Scheyern Experimental Farm of the Munich Research Association for Agricultural Ecosystems (FAM). The area, $40 \mathrm{~km}$ north of Munich, is part of the Tertiary hills, an important agricultural landscape in Central Europe. In one GWW (subsequently referred as unmanaged GWW), natural succession without any maintenance occurred for 8.5 years. The vegetation was dominated by fast-growing grasses (e.g. quack grass (Elytrigia repens (L.) Desv. ex Nevski), orchard grass (Dactylis glomerata L.), oat-grass (Arrhenatherum elatius (L.) P. Beauv. ex J. Presl \& C. Presl)), tall herbs (e.g., fireweed (Epilobium angustifolium L.), hemp-nettle (Galeopsis tetrahit L.), goose-grass (Galium aparine L.)), and a few woody plants (e.g. willow (Salix spp.), berries (Rubus spp.), rowan (Sorbus spp.)). This GWW was $22-48 \mathrm{~m}$ wide and $290 \mathrm{~m}$ long with a flat-bottomed cross-section. The average slope of the thalweg was $5.3 \%$ (Fig. 1). Along the thalweg colluvial soils could be found to a depth of about $1.5 \mathrm{~m}$ mainly formed by deposition from tillage

Thalweg morphology unmanaged grassed waterway

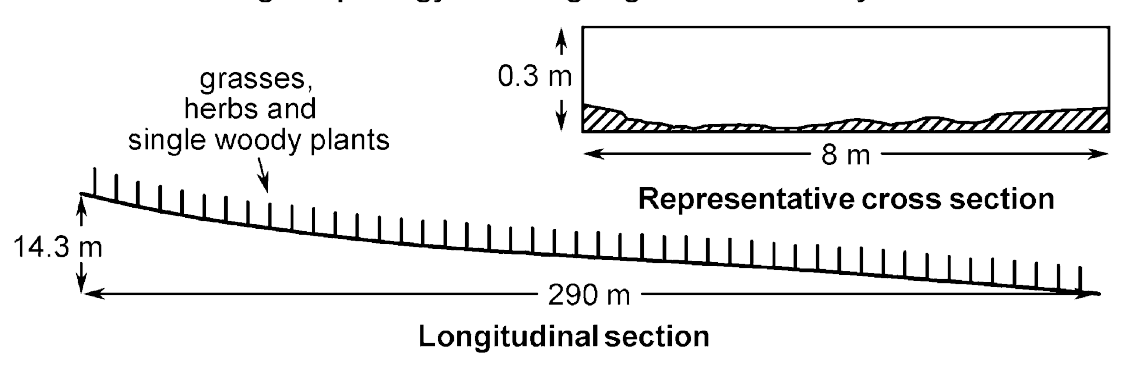

Thalweg morphology cut grassed waterway

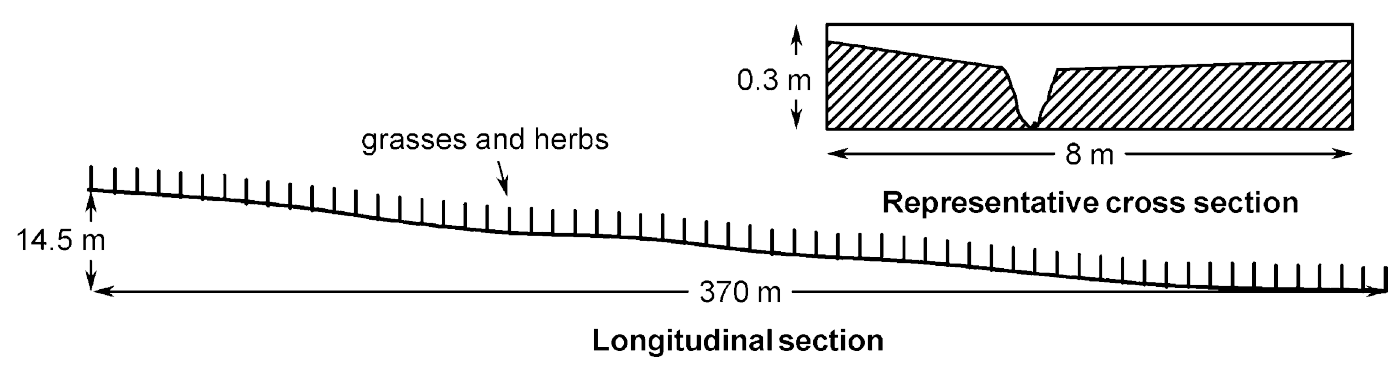

Fig. 1. Thalweg morphology of the tested grassed waterways. 
erosion. The second GWW (subsequently referred as cut GWW) was annually cut with a mulching mower at the beginning of August. Hence the vegetation was dominated by fast-growing grasses (e.g. quack grass, orchard grass, oat-grass) and a few herbs (e.g. nettle (Urtica dioica L.)), but no woody plants (Fiener and Auerswald, 2003a). In contrast to the unmanaged GWW, the cut GWW was frequently used for turning operations of agricultural machinery during management of the neighboring fields. The cut GWW was $10-25 \mathrm{~m}$ wide and $370 \mathrm{~m}$ long. The average slope of its thalweg was $4.1 \%$. The cross-section of the cut GWW was also flat-bottomed, but with a small incision along the thalweg that was about $50-80 \mathrm{~cm}$ wide and $15 \mathrm{~cm}$ deep (Fig. 1), which was the result of runoff events shortly after sowing in the grass in 1993. Similar to the unmanaged GWW, there were primarily colluvial soils along the thalweg to a depth of about $2 \mathrm{~m}$.

Typical for many small patterned and hilly agricultural areas in Europe, both GWWs drained relatively small watersheds. The watershed, where the unmanaged GWW was located, had a size of 7.9 ha and a mean slope of $9.3 \%$, while the cut GWW drained an area of 13.7 ha with a mean slope of 9.2 (Table 1). Due to the high runoff reduction capacity of the unmanaged GWW of about 90\% (Fiener and Auerswald, 2003b), the inflow into both GWWs was similar, because the watershed of the cut GWW includes the less runoff producing watershed of the unmanaged GWW.

\subsection{Experimental design}

The controlled experiment with the concentrated runoff was carried out on the second and third of October 2001. The weather was sunny on both days with an average temperature of 18.2 and $15.3^{\circ} \mathrm{C}$, respectively. From data provided by the German National Meteorological Service (DWD) for loamy soil under grass based on measured daily precipitation and calculated daily evapotranspiration, it can be expected that all fine and medium soil pores were filled with water (available field capacity $100 \%$ ). This should be a typical condition for a GWW for most of the year because a GWW receives water from runoff in addition to precipitation.

On the first day of the experiment, groundwater (temperature $10.5^{\circ} \mathrm{C}$ ) was pumped to the upstream end of the cut GWW and led concentrated into the thalweg. On the second day, the same was done in the unmanaged GWW. The inflow volume, in total $251 \mathrm{~m}^{3}$ in the cut GWW and $469 \mathrm{~m}^{3}$ in the unmanaged GWW, was measured with a calibrated water-meter.

Table 1

Site, GWW, and experimental conditions

\begin{tabular}{|c|c|c|}
\hline & Cut GWW & Unmanaged GWW \\
\hline \multicolumn{3}{|l|}{ Watershed characteristics } \\
\hline Size (ha) & 13.7 & 7.9 \\
\hline Average slope $(\%)$ & 9.2 & 9.3 \\
\hline \multicolumn{3}{|l|}{ GWW characteristics } \\
\hline Size (ha) & 0.58 & 1.06 \\
\hline Length (m) & 370 & 290 \\
\hline Width (m) & $10-25$ & $22-48$ \\
\hline Slope of the side-slopes $(\%)$ & 2.6 & 3.6 \\
\hline Slope along the thalweg $(\%)$ & 4.1 & 5.3 \\
\hline \multicolumn{3}{|l|}{ Soils } \\
\hline On the side-slopes & \multicolumn{2}{|c|}{ Loamy or silty loamy Inceptisols } \\
\hline Along the thalweg & \multicolumn{2}{|c|}{ Colluvial soils } \\
\hline Vegetation & Fast growing grasses and few herbs & Herbs, grasses and single woody plants \\
\hline Maintenance & Cut every year in July/August & Set a aside for 8.5 years \\
\hline \multicolumn{3}{|l|}{ Experimental conditions } \\
\hline Inflow $\left(1 \mathrm{~s}^{-1}\right)$ & 9.32 & 9.16 \\
\hline Soil moisture & \multicolumn{2}{|c|}{ All fine and medium pores filled with water } \\
\hline
\end{tabular}


The inflow rate, on average 9.32 and $9.161 \mathrm{~s}^{-1}$, respectively, was determined every $10 \mathrm{~min}$ (Table 1).

Both GWWs were bordered at their downstream end by small dams, from which runoff was transmitted via underground-tile outlets (pipes with a diameter of $29 \mathrm{~cm}$ ) to the measuring system. The measuring system was based on a Coshocton-type wheel runoff sampler similar to that used by Carter and Parsons (1967). The system collected an aliquot of about $0.5 \%$ from the total runoff coming from the outflow pipes and led it to a tipping bucket $(\sim 85 \mathrm{ml})$, which was connected to a Delta-T-Logger (Delta-T Devices Ltd, Cambridge, UK) that counted the number of tips. The system allowed calculating the outflow volume and rate during the experiment with an accuracy of $\pm 10 \%$. A detailed description and a precision test were presented by Fiener and Auerswald (2003b).

After inflow and outflow rates had become constant (steady-state runoff), the effective runoff widths and the runoff depths were measured at two representative cross-sections in each GWW, which were located at about one-third and two-third of the GWW length. From the average width at the crosssections and the length of each GWW, we calculated the area of infiltration. The average runoff depths at the cross-sections were used to determine the average runoff cross-section in each GWW. To calculate the runoff velocity and the hydraulic roughness at the cross-sections, we also measured their slope along the thalweg with a water scale.

In order to verify the average steady-state runoff velocity estimated from the measurements at the cross-sections, $\mathrm{NaCl}$ was used as a tracer to determine runoff travel time between inflow and outflow in the cut GWW. For this purpose 3001 water, with a $\mathrm{NaCl}$ concentration of $33 \mathrm{~g} \mathrm{l}^{-1}$, were emptied within a few seconds into the inflow of the cut GWW. After injecting the water, the electric conductivity of the outflow of the GWW was measured. The measurements were carried out till, after a clearly detectable peak conductivity, the conductivity in the outflow decreased to a level close to that before the injection of $\mathrm{NaCl}$.

\subsection{Modeling}

A schematic diagram of the flow in a GWW is represented in Fig. 2. A GWW can be divided in

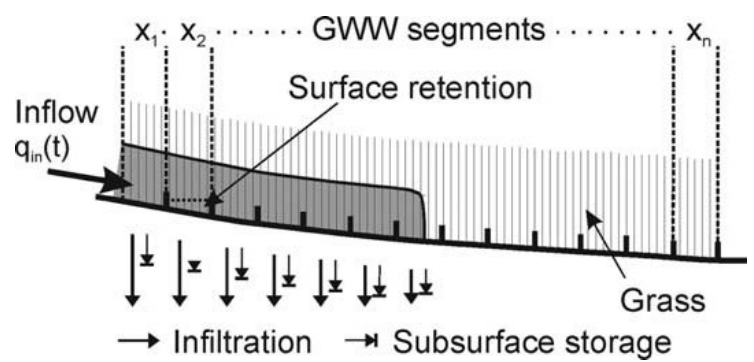

Fig. 2. Flow translocation concept used for modeling.

a number $n$ of segments with the length $\Delta x$. The inflow $q_{\text {in }}$ infiltrates in the first segment. Once the infiltration capacity of the soil is exceeded, the storage of this cell, which consists of surface retention in depressions and subsurface storage in channels of burrowing mammals, starts to fill. After the storage capacity of the first segment is also exceeded, surface runoff into the next segment occurs. Due to the ongoing infiltration in the first segment $q_{\text {in }}$ of the second segment is smaller than that of the first segment. To model the runoff in a GWW it is, hence, necessary to take three processes into account simultaneously: (1) infiltration, (2) filling of surface and subsurface storage and (3) surface runoff.

\subsubsection{Infiltration}

Infiltration in an initially unsaturated soil depends on soil conditions (especially soil moisture and texture) and soil type (horizontal variation). The process of horizontal and vertical infiltration in unsaturated soil is generally described by the Richard's equation (Hillel, 1998), which combines the continuity equation and Darcy's law (momentum equation). However, in case of the GWW, we assumed that vertical infiltration is the dominant process, while horizontal infiltration can be neglected. Therefore, we adopted the Philip's equation (Eq. (1)), which was the first mathematically rigorous solution of the Richard's equation applied to vertical infiltration (Hillel, 1998; Philip, 1969)

$i(t)=\frac{1}{2 \sqrt{t}} S+K$

where $i(t)$ is the infiltration rate $\left(\mathrm{m} \mathrm{s}^{-1}\right), t$ is the time (s), $S$ is the sorptivity $\left(\mathrm{m} \mathrm{s}^{-0.5}\right.$ ), and $K$ is the hydraulic conductivity $\left(\mathrm{m} \mathrm{s}^{-1}\right)$. 
Eq. (1) holds for the case of an infinitively deep homogeneous soil of a constant initial wetness, which is ponded by a thin layer of water. The water depth $h$ in the area of concentrated flow may influence the infiltration rate. According to Philip (1958), $i(t)$ increases by about $2 \%$ per centimeter of $h$ in case of a Yolo light clay and an infiltration time similar to that of the experiment. For the relatively small runoff depths observed in the GWWs (average $h \leq 0.06 \mathrm{~m}$ ), it was assumed that the condition of a thin layer was met. In areas, where GWWs are established, mostly deep colluvial soils can be found. Nevertheless, the first prerequisites of the Philip's equation are not satisfied because (1) in an upper soil layer to a depth between 0.8 and $1.0 \mathrm{~m}$ macropores can be found, mainly resulting from biological activity, e.g. burrowing animals, especially earthworms, and the presence of decayed roots. The underlying soil layer is not structured in this way and, hence, macropores are missing. (2) A constant initial wetness is only given if all fine and medium pores in the soil are filled with water. In the rooted soil (up to $1 \mathrm{~m}$ depth under the grasses and herbs), this is only the case if the water input by precipitation exceeds the water uptake of the vegetation. In general, the water filling of the macropores in the rooted soil exhibits a strong seasonal variation.

Due to the difference in structure and eventually water content in the upper and the lower soil layer (subsequently referred as structured and matrix soil layer, respectively), we calculated infiltration for both separately. For the structured soil layer, we applied Eq. (1), under the assumption that the coarse (macro) pores will be filled in case of ponding in a GWW. After the wetting front (Fig. 3) had reached the matrix soil layer at time $t_{x}$ we assumed that the sorptivity is filled up and further infiltration is ruled by the hydraulic conductivity in this soil layer $K_{\mathrm{msl}}\left(\mathrm{m} \mathrm{s}^{-1}\right)$

$i(t)=K_{\mathrm{msl}} \quad$ for $t>t_{x}$

To identify the time $t_{x}$, we used the integral of Eq. (1) to calculate the sum of infiltration $I(t)(\mathrm{m})$ :

$I(t)=S t^{1 / 2}+K t$

The term $S t^{1 / 2}$ represents the volume of water, which has infiltrated into the previously aerated medium and coarse (macro) pores after the time $t$. The wetting front has reached the matrix soil layer when $S t^{1 / 2}$

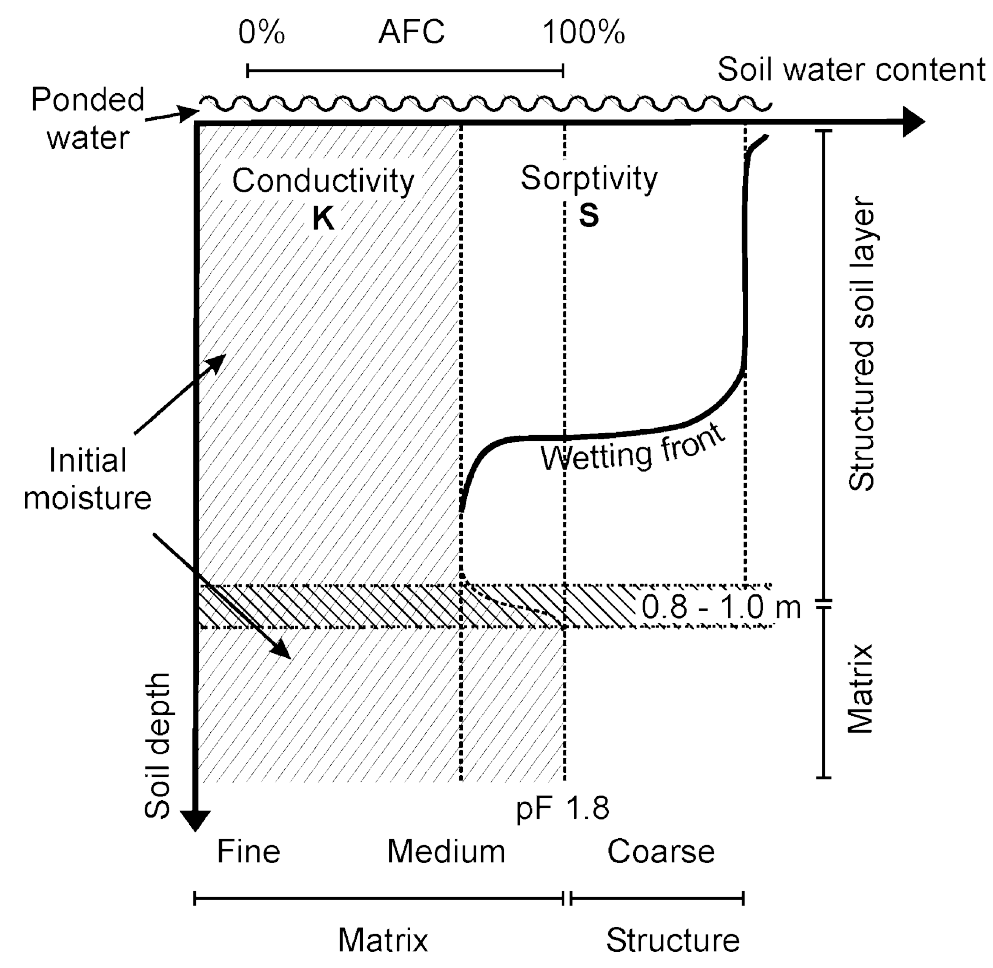

Fig. 3. Infiltration concept used for modeling. 
equals the total volume of aerated coarse and medium pores.

\subsubsection{Surface retention and subsurface storage}

The retention in surface depressions depends on the surface characteristics and the slope of a GWW. For grassed areas surface depression volume can be equal in magnitude to the total depth of a small to medium rainfall (Deletic, 2001). For the modeling, the volume was estimated to be equal to the measured runoff depth during the experiment.

During ponding not only the surface depressions are filled, but also the comparably large 'channels' from burrowing mammals are flooded, in case of the unmanaged GWW especially from mice. As these burrows build a network they fill up rapidly (observed during the experiment) and act as water storage similar to surface depressions. These burrows may also lead to preferential flow or return flow, but this was not taken into account for modeling because of their small extension compared to the length of the GWW. Their contribution to the infiltration process should be small because mice primarily build their network within the upper $20 \mathrm{~cm}$ of the soil and the comparably small surface of the burrows is compacted by the animals. Hence, we also neglected these 'channels' in case of infiltration.

\subsubsection{Surface runoff}

The general mathematical formulation of onedimensional hydraulic flow processes was first introduced by Saint-Venant in 1881. It bases on a combination of the continuity equation (Eq. (4)) and the momentum equation (Eq. (5)). For a small channel, where infiltration into the soil is a major process, it can be described as

$b \frac{\partial h}{\partial t}+\frac{\partial q}{\partial x}=q_{\text {in }}-q_{\text {out }}-i$

$\frac{\partial v}{\partial t}+v \frac{\partial v}{\partial x}+g \frac{\partial h}{\partial x}=g\left(S_{0}-S_{\mathrm{f}}\right)$

where $b$ is the runoff width $(\mathrm{m}), h(x, t)$ is the flow depth $(\mathrm{m}), q(x, t)$ is the discharge $\left(\mathrm{m}^{3} \mathrm{~s}^{-1}\right), x$ is the distance in flow direction $(\mathrm{m}), q_{\text {in }}$ is the inflow rate $\left(\mathrm{m}^{3} \mathrm{~s}^{-1}\right)$, $q_{\text {out }}$ is the outflow rate $\left(\mathrm{m}^{3} \mathrm{~s}^{-1}\right), v$ is the flow velocity $\left(\mathrm{m} \mathrm{s}^{-1}\right), g$ is the gravitational acceleration $\left(\mathrm{m} \mathrm{s}^{-2}\right), S_{0}$ and $S_{\mathrm{f}}$ are the dimensionless bed and friction slopes, respectively.

The kinematic wave approximation (Lighthill and Woolhiser, 1955), which was already successfully used for the modeling of surface runoff in vegetated filter strips (Deletic, 2001; Munoz-Carpena et al., 1993, 1999) and which is popular for simulating flows in channels (Singh, 2001), is a simplification of the Saint-Venant equations. It is based on the assumption that for specific runoff conditions, which are given in case of overland flow and shallow surface runoff in small channels, the terms on the left-hand side of Eq. (5) can be neglected. Hence, the momentum equation results in $S_{0}=S_{\mathrm{f}}$. In that case the relationship between $q$ and $h$ in Eq. (4) can be expressed by the often-used Manning's equation (Eq. (6))

$q=\frac{1}{n} S_{0}^{1 / 2} R^{2 / 3} A$

where $n$ is the Manning's roughness coefficient $\left(\mathrm{s} \mathrm{m}^{-1 / 3}\right)$ depending on soil surface conditions and vegetative cover, $A$ is the cross-sectional area of the flow $\left(\mathrm{m}^{2}\right)$, and $R$ is the hydraulic radius (m).

$R$ in channels can be expressed as $R=A / P$, where $P$ is the hydraulic perimeter. The hydraulic perimeter in flat-bottomed channels with low runoff depths can be approximated by the channel width $b$. For an idealized cross-section of a GWW (Fig. 4) with flow depth $d, A$ can be expressed as $A=1 / 2 d b$ and $b$ can be written as $b=2 d / \tan \alpha$. Taking $h=d / 2$, Manning's equation can be rearranged as:

$q=\frac{1}{n} S_{0}^{1 / 2} h^{8 / 3} \frac{4}{\tan \alpha}$

We used this equation for modeling the discharge in the GWW under the assumption of a constant slope along the thalweg $S_{0}$ and a constant channel side-slope $\alpha$ (Fig. 4) over its total length.

\subsubsection{Parameterization}

The model was fitted to the observed data of the GWW experiments varying only one parameter,

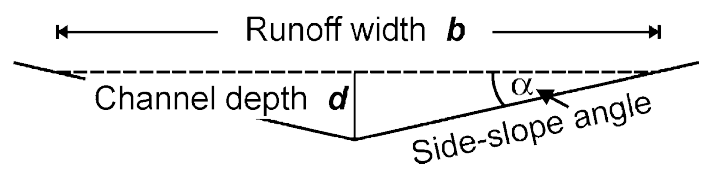

Fig. 4. Generalized runoff cross-section. 
sorptivity. GWW morphology was parameterized by the length of each GWW, the average slope along the thalweg and the average effective runoff width measured during the experiment. According to the water content modeling of the DWD (Löpmeier, 1994) all fine and medium soil pores were filled with water at the beginning of the experiments, hence we used the same hydraulic conductivity for the structured and the matrix soil layer. Assuming that in case of steady-state outflow from the GWWs infiltration, rate is only ruled by the hydraulic conductivity $K_{\mathrm{msl}}$ in the matrix soil layer, $K$ was calculated using Eq. (2) and the steady-state outflow rates. The pore size distribution of the medium pores and the coarse (structural) pores in the structured soil layer of both GWWs were adopted from measurements and pedotransfer functions from Scheinost et al. (1997). Due to the fact that cutting or grazing of grass affect the biomass and the length of its roots (Dawson et al., 1999), it was assumed that the rooting depth in the cut GWW was slightly smaller than in the unmanaged GWW, where even some woody plants were located. This was taken into account calculating the air filled pores in each GWW. The average Manning's $n$ was calculated from the measurements at representative cross-sections. All model input parameters were summarized in Table 2.

\section{Results and discussion}

\subsection{Experiment}

The controlled experiment confirmed the higher efficacy in runoff reduction of the unmanaged GWW compared to the cut GWW that was already evident from the long-term landscape experiment between 1994 and 2000 (Fiener and Auerswald, 2003b). The total inflow volume into the cut GWW of $251 \mathrm{~m}^{3}$ created an outflow volume of $128 \mathrm{~m}^{3}$. In the unmanaged GWW an inflow volume of $469 \mathrm{~m}^{3}$ was reduced to an outflow volume of $46 \mathrm{~m}^{3}$. The time between inflow and outflow (subsequently referred as time to runoff $t_{\mathrm{r}}$ ) was about $3 \mathrm{~h}$ in the cut and $12 \mathrm{~h}$ in the unmanaged GWW. The maximum outflow rates were 6.6 and $4.21 \mathrm{~s}^{-1}$, respectively (Fig. 5).

In case of steady-state flow, the average runoff width and depth, measured at the two cross-sections in each GWW, were $1.9 \mathrm{~m}( \pm 32 \%)$ and $0.06 \mathrm{~m}$ $( \pm 25 \%)$, respectively, in the cut GWW, and $7.35 \mathrm{~m}$ $( \pm 20 \%)$ and $0.03 \mathrm{~m}( \pm 10 \%)$, respectively, in the unmanaged GWW. From these measurements the average runoff cross-section $A$ was calculated (cut $\mathrm{GWW}=0.114 \mathrm{~m}^{2}$, unmanaged $\mathrm{GWW}=0.221 \mathrm{~m}^{2}$ ). Assuming for steady-state flow conditions, a linear

Table 2

Parameters used to fit the model to the experimental data

\begin{tabular}{|c|c|c|c|c|c|}
\hline Characteristics & Model parameter & Symbol & Unit & Cut GWW & $\begin{array}{l}\text { Unmanaged } \\
\text { GWW }\end{array}$ \\
\hline \multirow{3}{*}{$\begin{array}{l}\text { GWW mor- } \\
\text { phology }\end{array}$} & Length & $L$ & $\mathrm{~m}$ & 370 & 290 \\
\hline & Effective runoff width & $b$ & $\mathrm{~m}$ & 1.90 & 7.35 \\
\hline & Slope & $S_{0}$ & $\%$ & 4.1 & 5.3 \\
\hline \multirow[t]{10}{*}{ Soil } & Sorptivity & $S$ & $\mathrm{~m} \mathrm{~s}^{-0.5}$ & $8.7 \times 10^{-4}$ & $1.00 \times 10^{-3}$ \\
\hline & Hydraulic conductivity & & & & \\
\hline & Structured soil layer & $K_{\mathrm{ssl}}$ & $\mathrm{m} \mathrm{s}^{-1}$ & $4.1 \times 10^{-6}$ & $2.4 \times 10^{-6}$ \\
\hline & Matrix soil layer & $K_{\mathrm{msl}}$ & $\mathrm{m} \mathrm{s}^{-1}$ & $4.1 \times 10^{-6}$ & $2.4 \times 10^{-6}$ \\
\hline & $\begin{array}{l}\text { Depth structure/matrix pore soil layer } \\
\text { boundary }\end{array}$ & - & $\mathrm{m}$ & 1.0 & 1.0 \\
\hline & Characteristics structured soil layer & & & & \\
\hline & Medium pores & - & $1 \mathrm{~m}^{-2}$ & 160 & 183 \\
\hline & Coarse (structure) pores & - & $1 m^{-2}$ & 72 & 100 \\
\hline & Air filled pores & - & $1 \mathrm{~m}^{-2}$ & 72 & 100 \\
\hline & Volume of mouse holes & - & $1 \mathrm{~m}^{-2}$ & 3.0 & 3.0 \\
\hline \multirow[t]{2}{*}{ Vegetation } & Manning's $n$ & $n$ & $\mathrm{~s} \mathrm{~m}^{-1 / 3}$ & 0.38 & 0.36 \\
\hline & Rooting depth & & $\mathrm{m}$ & 0.8 & 0.9 \\
\hline
\end{tabular}




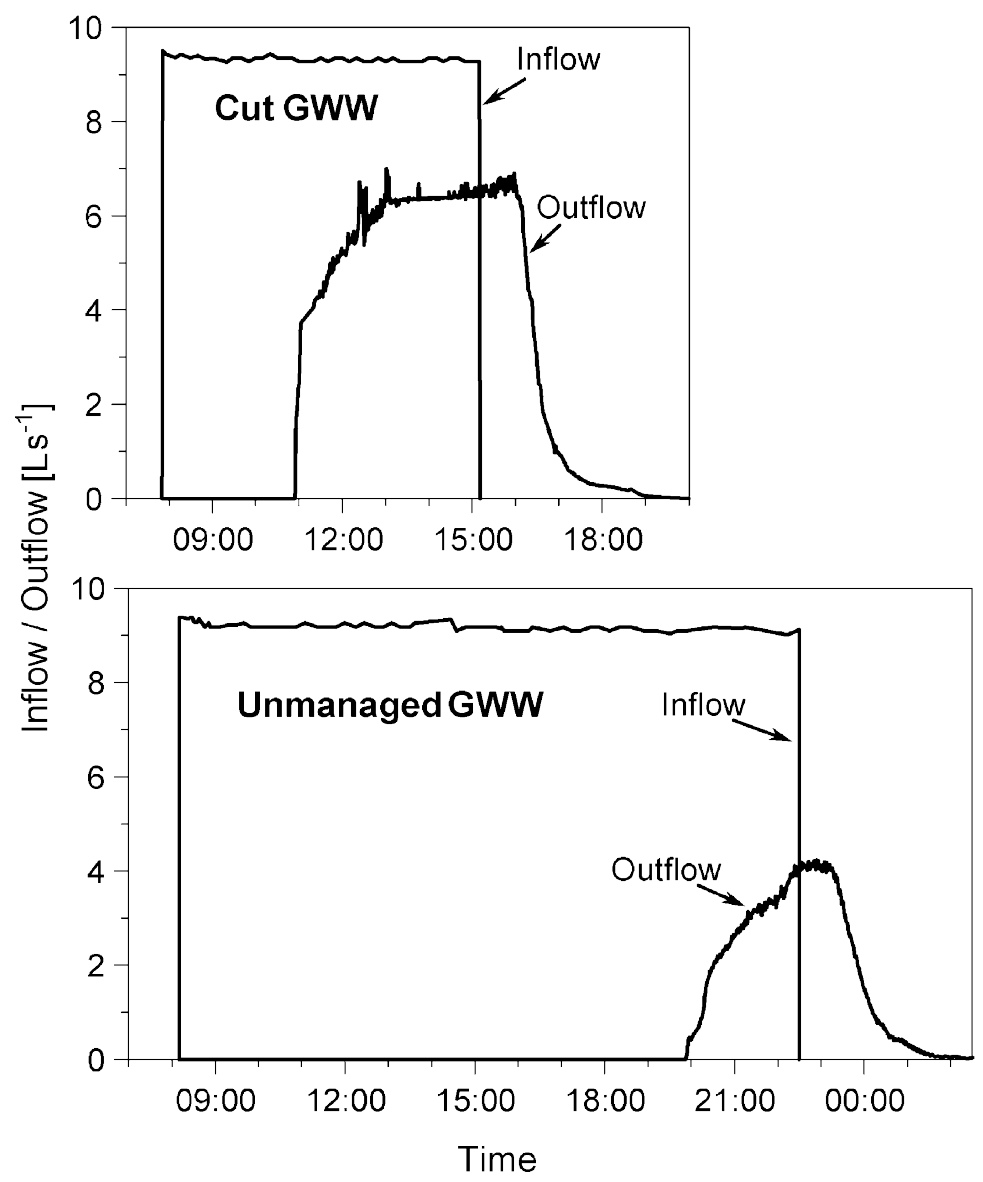

Fig. 5. Inflow and outflow hydrograph measured in the cut and in the unmanaged grassed waterway.

decrease of the runoff rate along the thalweg, the runoff rate $q$ at each of the representative crosssections was estimated. As the runoff velocity $v$ can be expressed as $v=q / A$, the average runoff velocity was calculated for both GWWs. In the cut GWW, it averaged $0.073 \mathrm{~m} \mathrm{~s}^{-1}$ and in the unmanaged GWW $0.046 \mathrm{~m} \mathrm{~s}^{-1}$. The calculations for the cut GWW were confirmed using the data from labeling the runoff with $\mathrm{NaCl}$. Assuming that the average runoff travel time was equal to the time span between $\mathrm{NaCl}$ input and the $\mathrm{NaCl}$ peak concentration in the outflow, the runoff velocity averaged $0.077 \mathrm{~m} \mathrm{~s}^{-1}$. Assuming that the average runoff travel time was reached after half of the total $\mathrm{NaCl}$ outflow has passed the measuring system, the runoff velocity averaged $0.071 \mathrm{~m} \mathrm{~s}^{-1}$.

According to Eq. (6), we calculated the hydraulic roughness coefficients (Manning's $n$ ) for the representative cross-sections. In the cut GWW, Manning's $n$ averaged $0.38 \mathrm{~m} \mathrm{~s}^{-1 / 3}$, in the unmanaged GWW
$0.36 \mathrm{~m} \mathrm{~s}^{-1 / 3}$. These values, which were in a typical range for dense non-submerged grass (Jin et al., 2000; Kouwen, 1992), were used for modeling. The area of infiltration in each GWW was calculated from the measured runoff width and the length of each GWW. It was $703 \mathrm{~m}^{2}$ in the cut and $2132 \mathrm{~m}^{2}$ in the unmanaged GWW.

\subsection{Modeling}

Comparing the simulated and the observed data in the cut GWW indicated a generally good prediction (Fig. 6a). Plotting the predicted data against the observed data shows a nearly perfect agreement between model results and observation (Fig. 6b), with a $R^{2}=0.93$ and a regression line close to the $1: 1$ line (line of perfect agreement).

In case of the unmanaged GWW also a good prediction was obtained (Fig. 6c). Only the time to 


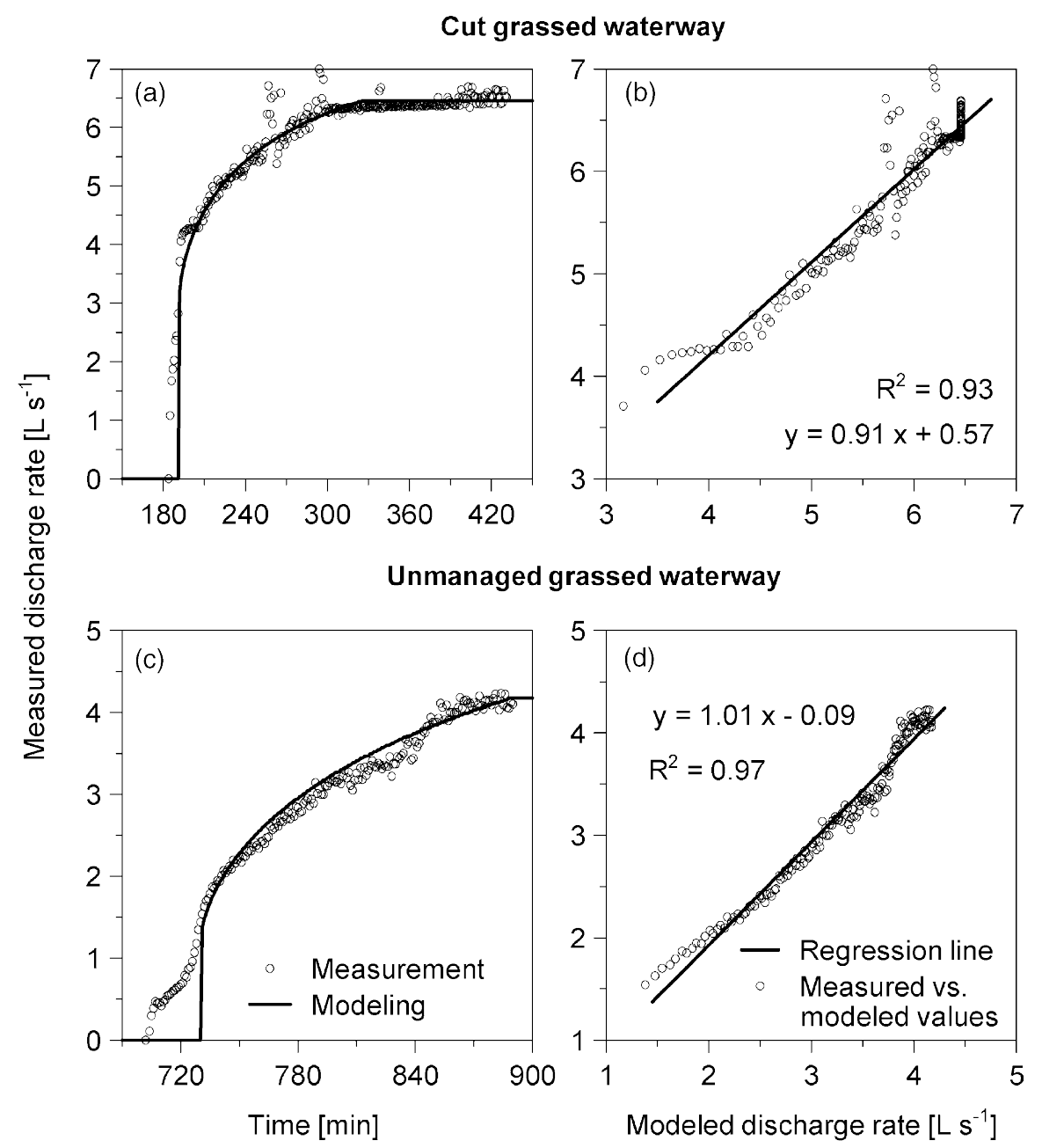

Fig. 6. Comparison between measured and modeled runoff in the cut and in the unmanaged grassed waterway.

runoff was over predicted, a fact that can be explained by field observations during the experiment. About $20 \mathrm{~min}$ before the clearly defined waterfront reached the outflow of the GWW, runoff was passing through a mouse hole, which ended close to the measuring system. In consequence a small outflow (maximum rate $0.751 \mathrm{~s} \mathrm{~s}^{-1}$ ) occurred, which rapidly increased after 20 min when the waterfront reached the down slope end of the GWW. This preferential flow through a mouse hole (a clear indicator for a rapid filling of the mouse holes that have been taken into account as subsurface storage) could not be predicted with the model approach. Due to their small contribution to the total time to and volume of runoff, initial runoff rates were neglected when plotting the predicted against the observed data (Fig. 6d). In this case the predicted data explained $97 \%$ of the observed data and the regression line was also close to the 1:1 line.

The model input parameters (Table 2) used to fit the model to the observed data indicate that the effective runoff width mainly accounted for the difference between both GWWs, which was already identified as important factor during the experiment.

However, to examine whether also the differences in soil conditions, found for the best-fit modeling, were important parameters for differences in runoff characteristics or whether only the GWW's morphology parameters were dominant, a sensitivity analysis was performed. This can also help to optimize the layout of GWWs for runoff reduction. 


\subsection{Sensitivity analysis}

The model parameters were varied within the ranges presented in Table 3. During the model runs all parameters were kept constant at the value determined from the experiment, except for the one, which was varied. The following parameters were evaluated: (1) GWW's morphology (length, width, slope), (2) soil characteristics (hydraulic conductivity and sorptivity in the structured soil layer, hydraulic conductivity in the matrix soil layer), (3) vegetation characteristics (rooting depth, hydraulic roughness), and (4) water input parameters (inflow rate, short heavy rain before inflow, moderate rain during flow in the GWW).

The specific parameter ranges studied were as follows: (1) The parameters selected for GWW's morphology ranged between the half and the double of the measured values.
(2) To vary the hydraulic conductivity $K_{\text {ssl }}$ and the sorptivity $S$ in the structured soil layer the interdependency of both parameters must be taken into account. The relation between air filled pores (parameter used in the model to account for soil moisture) and $K_{\text {ssl }}$ was adopted from measurements carried out at the research farm (Scheinost, 1995; Scheinost et al., 1997). The relation between air filled pores and $S$ was determined fitting modeled to measured runoff rates in the cut GWW (Fig. 7). For the hydraulic conductivity in the matrix soil layer values between $10^{-9}$ and $10^{-3} \mathrm{~m} \mathrm{~s}^{-1}$ were used, covering the whole range of saturated hydraulic conductivity in different soils (Schachtschabel et al., 1992).

(3) For the rooting depth it was assumed that realistic values range between 0.6 and $1.0 \mathrm{~m}$. The values of Manning's $n$ were varied between 0.05 and $0.4 \mathrm{~m} \mathrm{~s}^{-1 / 3}$, which is the range of measured values for dense grasses under different runoff velocities,

Table 3

Best-fit model parameters in the cut GWW and their range for of the sensitivity analysis

\begin{tabular}{|c|c|c|c|c|c|c|}
\hline Characteristics & Model parameter & Symbol & Unit & Minimum & Best-fit value & Maximum \\
\hline \multirow{3}{*}{$\begin{array}{l}\text { GWW mor- } \\
\text { phology }\end{array}$} & Length & $L$ & $\mathrm{~m}$ & 185 & 370 & 740 \\
\hline & $\begin{array}{l}\text { Runoff width } \\
\text { (shape of cross- } \\
\text { section) }\end{array}$ & $b$ & $\mathrm{~m}$ & 0.95 & 1.90 & 3.80 \\
\hline & Slope & $S_{0}$ & $\%$ & 2.0 & 4.1 & 6.0 \\
\hline \multirow[t]{5}{*}{ Soil } & $\begin{array}{l}\text { Sorptivity } \\
\text { Hydraulic con- } \\
\text { ductivity }\end{array}$ & $S$ & $\mathrm{~m} \mathrm{~s}^{-0.5}$ & 0 & $8.7 \times 10^{-4}$ & $2.03 \times 10^{-3}$ \\
\hline & $\begin{array}{l}\text { Structured soil } \\
\text { layer }\end{array}$ & $K_{\text {ssl }}$ & $\mathrm{m} \mathrm{s}^{-1}$ & $1.7 \times 10^{-8}$ & $4.1 \times 10^{-6}$ & $3.1 \times 10^{-4}$ \\
\hline & $\begin{array}{l}\text { Matrix soil } \\
\text { layer }\end{array}$ & $K_{\mathrm{msl}}$ & $\mathrm{m} \mathrm{s}^{-1}$ & $1.0 \times 10^{-9}$ & $4.1 \times 10^{-6}$ & $1.0 \times 10^{-3}$ \\
\hline & $\begin{array}{l}\text { Depth structure/ } \\
\text { matrix pore soil } \\
\text { layer boundary }\end{array}$ & - & $\mathrm{m}$ & 0.8 & 1.0 & 1.0 \\
\hline & Air filled pores & - & $1 \mathrm{~m}^{-2}$ & 0 & 72 & 172 \\
\hline Vegetation & $\begin{array}{l}\text { Manning's } n \\
\text { Rooting depth }\end{array}$ & $n$ & $\begin{array}{l}\mathrm{s} \mathrm{m}^{-1 / 3} \\
\mathrm{~m}\end{array}$ & $\begin{array}{l}0.05 \\
0.6\end{array}$ & $\begin{array}{l}0.38 \\
0.8\end{array}$ & $\begin{array}{l}0.40 \\
1.0\end{array}$ \\
\hline \multirow[t]{3}{*}{ Input } & $\begin{array}{l}\text { Inflow } \\
\text { Rain }\end{array}$ & $q_{\text {in }}$ & $1 \mathrm{~s}^{-1}$ & 5.0 & 9.32 & 48.0 \\
\hline & Before inflow & $P_{\mathrm{b}}$ & $\mathrm{mm}$ & 0 & 0 & 30 \\
\hline & $\begin{array}{l}\text { Simultaneous } \\
\text { to concentrated } \\
\text { runoff }\end{array}$ & $P_{\mathrm{s}}$ & $\mathrm{mm} \mathrm{h}^{-1}$ & 0 & 0 & 15 \\
\hline
\end{tabular}

\footnotetext{
${ }^{a}$ When changing the rooting depth a water suction of $\mathrm{p} F 3.2$ (air filled pores $=172 \mathrm{l} \mathrm{m}^{-2}$ ) was assumed representing dry conditions at the test site.
} 


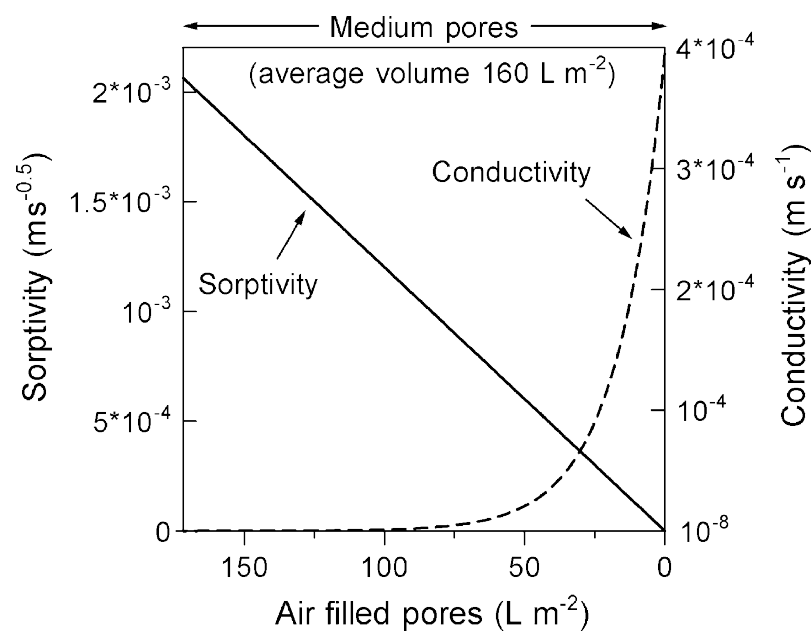

Fig. 7. Relationship between volume of total air filled pores and sorptivity and conductivity, data for the sorptivity were determined fitting modeled to measured runoff rates in the cut grassed waterway, data of conductivity were adopted from Scheinost (1995) and Scheinost et al. (1997).

runoff depths (submerged and unsubmerged) and slopes found in literature (Jin et al., 2000; Kouwen, 1992; Ogunlela and Makanjuola, 2000).

(4) For a realistic variation of the inflow rates the following evaluations and estimates were necessary: (i) the return period of different storms at the research farm were calculated from precipitation data collected between 1951 and 1980 at a neighboring $(1 \mathrm{~km})$ meteorological station. (ii) According to measurements of precipitation and runoff volume in the watershed with the GWW between 1994 and 2001 (Fiener and Auerswald, 2003b), the Curve Numbers in the watershed were calculated for the 10 heaviest rain events. This was done following the procedures of the SCS Curve Number model (Mockus, 1972). The average Curve Number for these rain events was 55 $(\mathrm{SD}=8)$, while the rains had a return period ranging from 0.5 to 5 years. (iii) With this Curve Number the runoff volumes of $12 \mathrm{~h}$ rain events with different return periods were calculated (Mockus, 1972) for the watershed with the GWW. (iv) We modeled runoff outflow from the GWW with our model for these runoff volumes, assuming an inflow period of $12 \mathrm{~h}$ in each case. For the sensitivity analysis we used inflow rates representing storms with return periods of 1,5 , and 10 years, respectively. Moreover, to simulate a 'worst case' scenario in which vegetation is flattened by high flow rates, we combined a storm with a return period of 10 years with the lowest values of Manning's $n$ documented in literature (see above).

To evaluate the influence of preceding or concomitant rain two situations were supposed: A short heavy rain between 5 and $30 \mathrm{~mm}$ before inflow occurs. A long moderate rain with an intensity of $5-15 \mathrm{~mm} \mathrm{~h}^{-1}$ occurring simultaneously to the inflow into the GWW.

The results of varying the parameters of GWW's morphology, soil and vegetation are presented for runoff volume in Figs. 8 and 9, and for time to runoff in Fig. 10. Clearly, the GWW's length and width had the biggest effect on runoff control, while the slope of the GWW was not prominent. Changing the length is marginally more effective than changing the width. For example, doubling the measured length or width in case of $10 \mathrm{~h}$ inflow, reduced outflow by 96 and $92 \%$, respectively. However, in designing a GWW it is much easier to enlarge the effective runoff width by creating a flat-bottomed cross-section (small angle $\alpha$ in Fig. 4) than to prolong the GWW's length. Hence, runoff width is the most important morphology parameter to control runoff.

Apparently, the runoff volumes were also highly sensitive to the hydraulic conductivity in the matrix soil layer, if the $K_{\mathrm{msl}}$ values were larger than $10^{-6} \mathrm{~m} \mathrm{~s}^{-1}$ (at the research farm this was only found for a few colluvial soils). For $K_{\mathrm{msl}}$ values between $10^{-9}$ and $10^{-6} \mathrm{~m} \mathrm{~s}^{-1}$, which represents typical soils found at the research farm (coarse-loamy and loamy-skeletal inceptisols), the runoff was not sensitive. At the tested GWWs, $K_{\mathrm{msl}}$ influenced infiltration only at long inflow times, when the infiltration front had passed the boundary between structured and matrix soil layer. In contrast the sensitivity of the runoff volume to a change in the structured soil ( $S$ and $K_{\text {ssl }}$ ) was small in case of inflow times $>5 \mathrm{~h}$, but important for inflow times $<5 \mathrm{~h}$.

Decreasing Manning's $n$ from $0.4 \mathrm{~m} \mathrm{~s}^{-1 / 3}$, which is similar to the measured values, to $0.05 \mathrm{~m} \mathrm{~s}^{-1 / 3}$, which is about the minimal value for dense grasses found in literature, decreased the runoff volume reduction of the GWW by about a factor 2 . Such a decrease in Manning's $n$ by about one order of magnitude can only be expected if the grass becomes submerged or bent to the ground because the hydraulic forces overcome the grass stem stiffness (Kouwen, 1992). Therefore, in respect to an optimized 


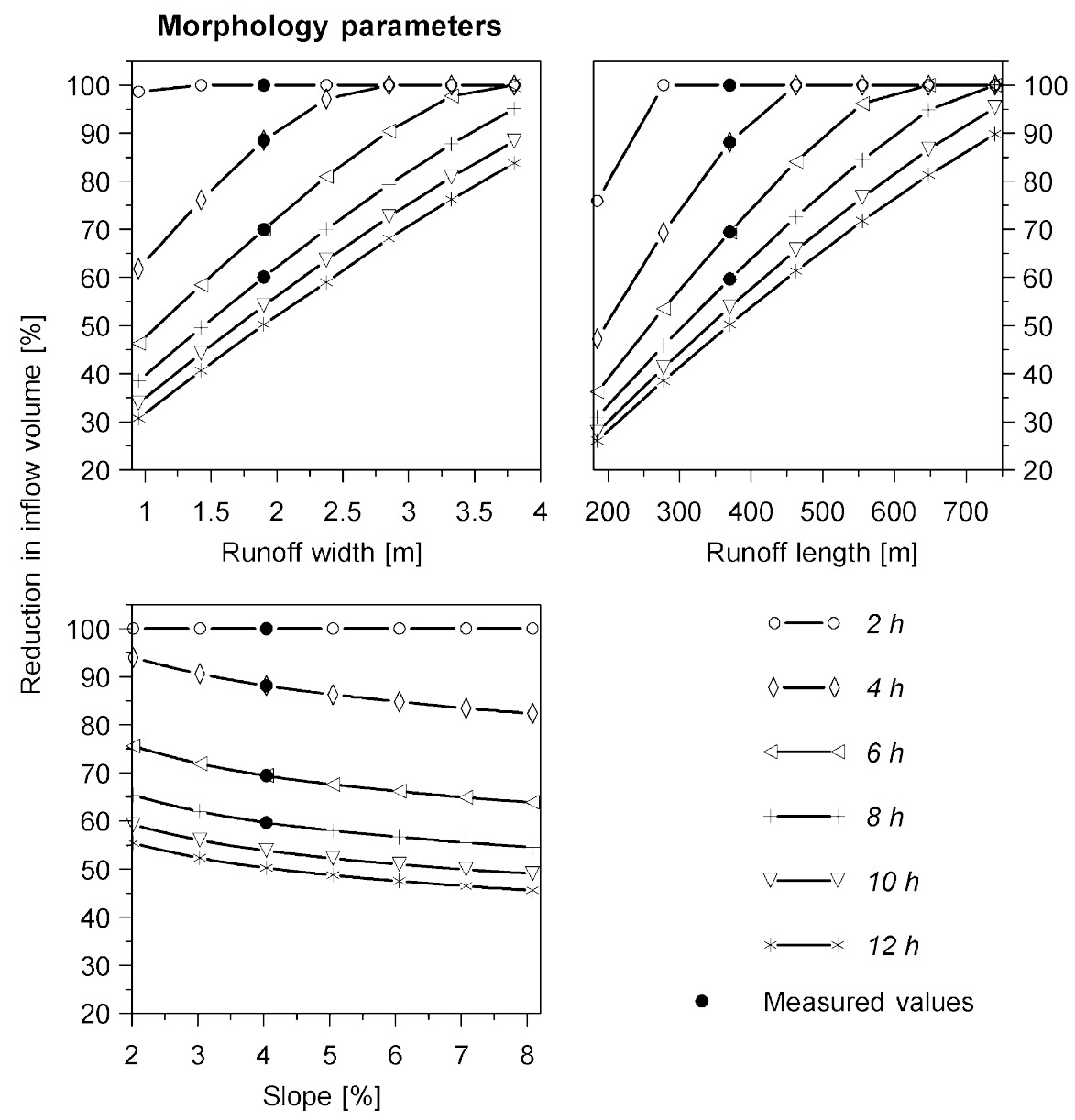

Fig. 8. Sensitivity of runoff volume outputs to variation in grassed waterway morphology.

runoff reduction, the design and the management of a GWW should support the stiffness of the vegetation and prevent submergence. This includes a flatbottomed GWW cross-section, the selection of appropriate species, mowing not earlier than after the development of stiff stems and an adequate stem height after mowing. Increasing the rooting depth had only an effect in case of dry soil conditions, because then it affects the total volume of air filled pores in the structured soil layer. However, this effect was marginal and it decreased with increasing inflow time.

Time to runoff $t_{\mathrm{r}}$ was again dominated by the GWW's length and width. Doubling the measured length and width increased $t_{\mathrm{r}} 2.9$ - and 2.3-fold, respectively. Again GWW's slope had a clearly smaller influence than other GWW morphology parameters. The modeled results were also sensitive to Manning's $n$ and the characteristics of the structured soil layer. Time to runoff was insensitive to the hydraulic conductivity in the matrix soil layer and to the rooting depth, because both parameters affect mainly the long-term infiltration rate and volume. This is true for the cut GWW with $t_{\mathrm{r}}$ $184 \mathrm{~min}$, while there is a small influence on the unmanaged GWW, where time to runoff was $704 \mathrm{~min}$.

Among the water input parameters (Fig. 11), the inflow rate had the most distinct effect on runoff control (Fig. 11a). It is generally the most dominant parameter governing the runoff characteristics in a GWW. Modeling an inflow rate of $271 \mathrm{~s}^{-1}$ (5-year storm) and $48 \mathrm{l} \mathrm{s}^{-1}$ (10-year storm) decreased time to runoff by 51 and $63 \%$, increased runoff volume by 420 and $823 \%$, and peak discharge rate by 350 and $657 \%$, respectively, compared to inflow rate of $9.31 \mathrm{~s}^{-1}$ 

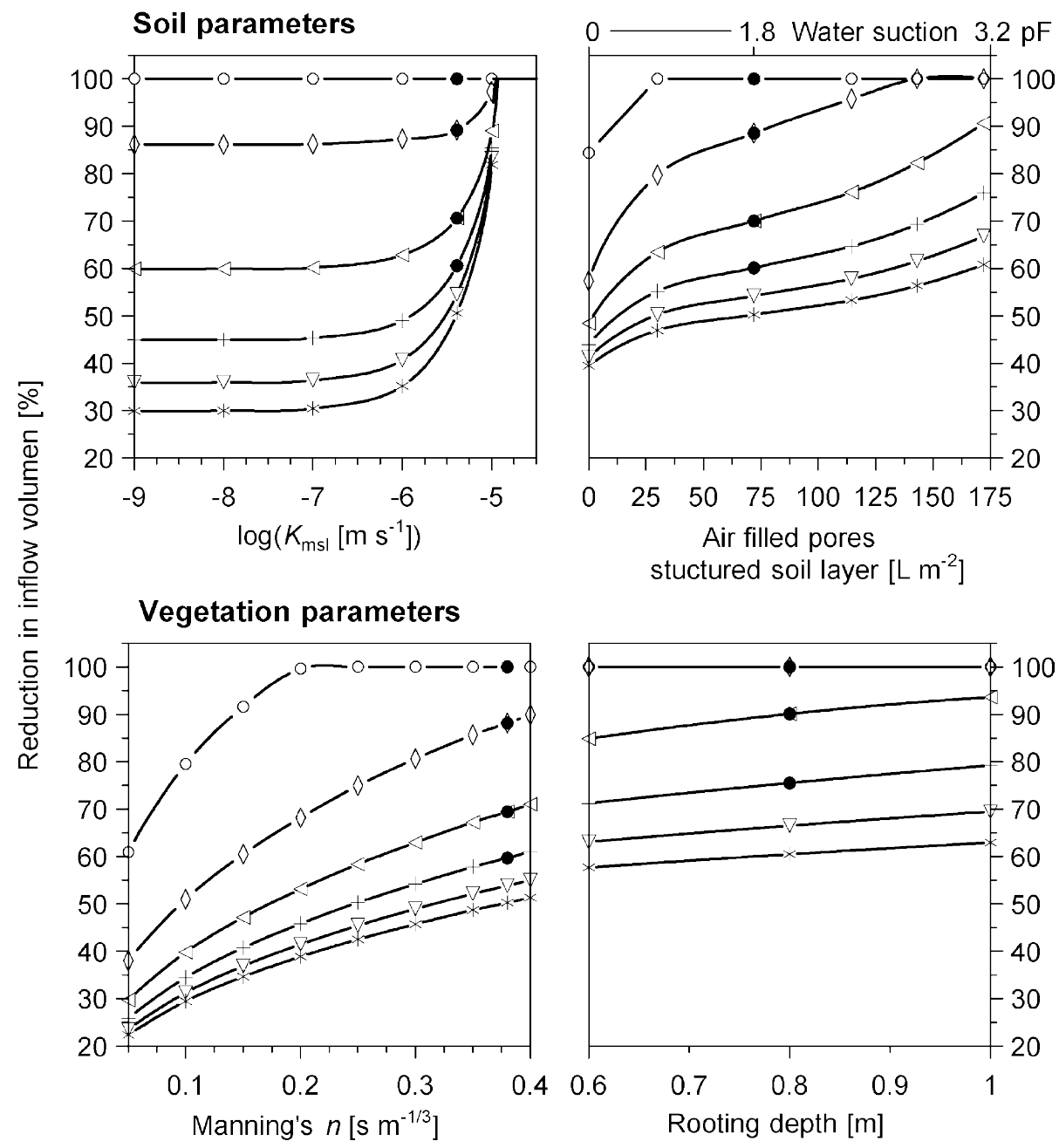

Fig. 9. Sensitivity of runoff volume outputs to variation in grassed waterway soil and vegetation parameters; except for the rooting depth only the shown parameter was varied; for the rooting depth dry soil conditions ( $\mathrm{p} F$ 3.2) were assumed; symbols are explained in Fig. 8.

( 3-year storm) applied during the experiment. For the 'worst case' scenario, where Manning's $n$ drops to values of $0.05 \mathrm{~m} \mathrm{~s}^{-1 / 3}$ in case of a 10 -year storm, the time to runoff decreased by $74 \%$, while runoff volume and peak discharge rate increased by 891 and $684 \%$, respectively, compared to the 3-year storm.

The Curve Number for our management system was extraordinarily low. It resulted mainly from the application of mulch tillage in combination with an optimized residue, tillage and crop management, small field sizes and the use of ultra-wide tires, which maintained the soil cover of over $50 \%$ throughout the year (Auerswald et al., 2000). The measured Curve Number meets the prediction for this soil cover
(Auerswald and Haider, 1996), whereas much higher runoff volumes can be expected for conventional farming. This would reduce the efficiency of the GWW dramatically. Hence, such a type of GWW is not an end-of-pipe erosion control but its effect increases the better the on-site erosion control is.

The sensitivity to rain occurring simultaneously to the concentrated inflow (Fig. 11b) was comparably small. There was hardly any effect on time to runoff, while the effect on runoff volume increased with increasing inflow and rain duration. The sensitivity of the peak discharge rate was also marginal compared to the effects of changing the inflow rate, because even in case of a rain intensity of $15 \mathrm{~mm} \mathrm{~h}^{-1}$ the water input 
Morphology parameters
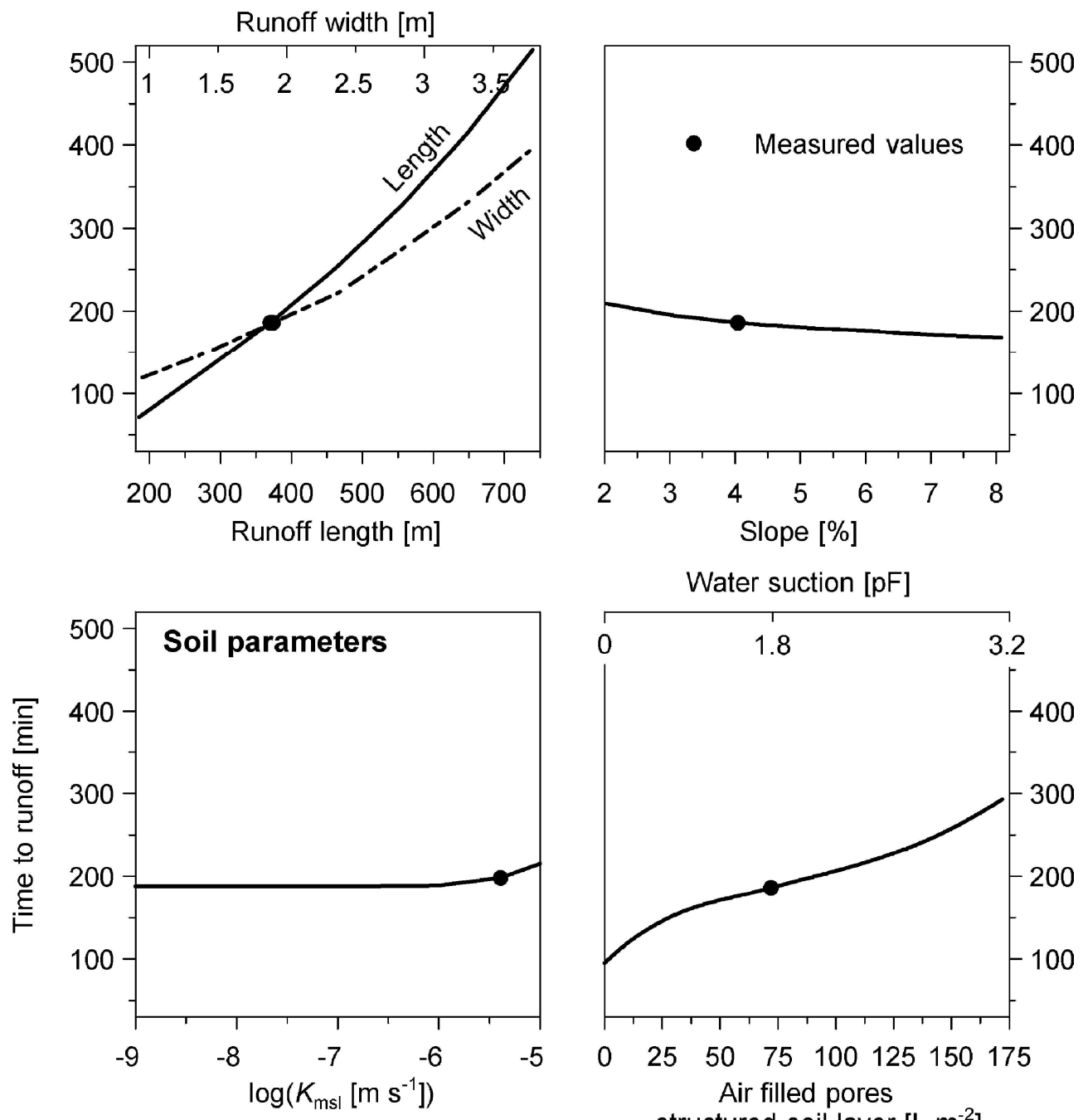

structured soil layer $\left[\mathrm{L} \mathrm{m}^{-2}\right]$
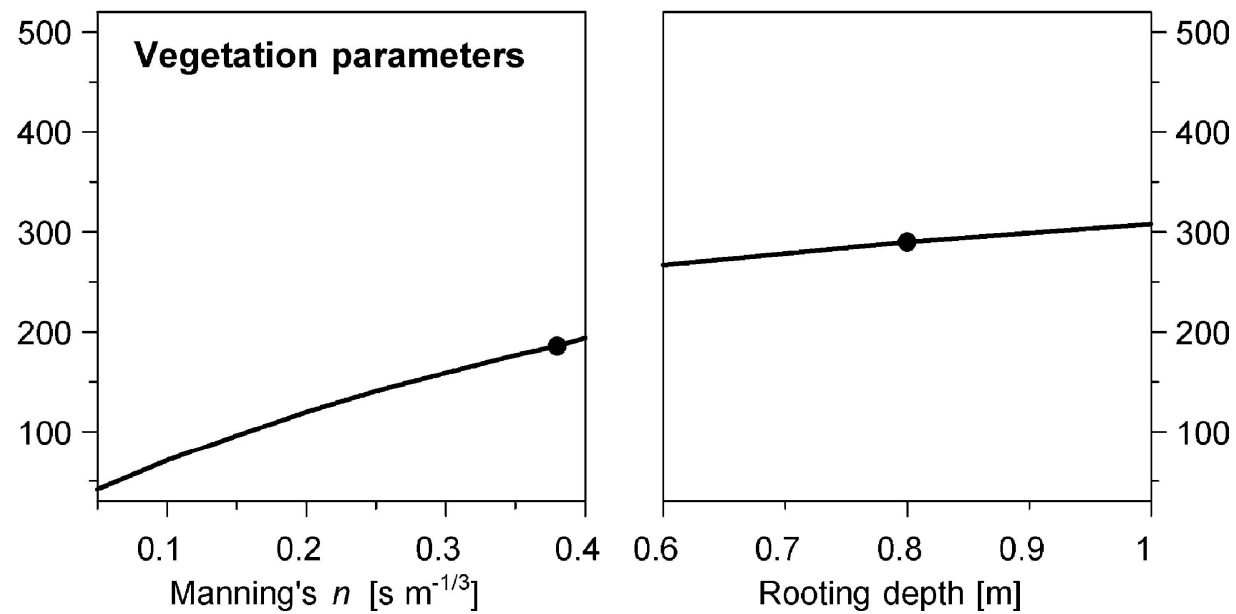

Fig. 10. Sensitivity of time to runoff; except for the rooting depth only the shown parameter was varied; for the rooting depth dry soil conditions ( $\mathrm{p} F$ 3.2) were assumed. 

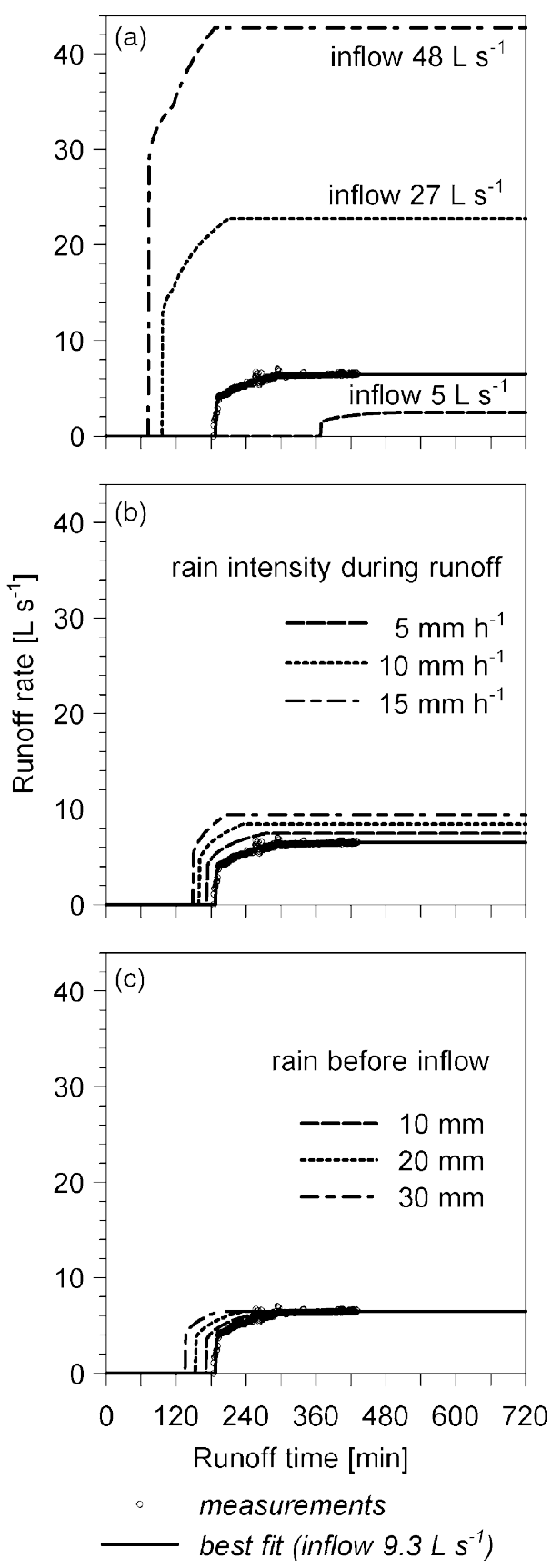

Fig. 11. Sensitivity of outflow hydrographs to variation in water input parameters; inflow rates in (a) were varied according to estimates of 1-, 5-, and 10-years storms, respectively (equivalent to 32,48 , and $56 \mathrm{~mm} / 12 \mathrm{~h}$ rains, causing inflow rates of 5,27 , and $481 \mathrm{~s}^{-1}$, respectively).

was only equivalent to an increase in inflow rate of about $3.01 \mathrm{~s}^{-1}$.

The influence of rain before inflow into the GWW occurred was small (Fig. 11c). A noticeable effect was only modeled for time to runoff, which was reduced by rain before inflow. The slight influence on runoff volume decreased with increasing inflow time.

\section{Conclusions}

The experimental results indicated large differences in runoff characteristics between the two tested GWWs, but did not show the reasons for these differences. The different behavior was successfully modeled by a complex dynamic model, combining Philip's (1969) infiltration equation with a kinematic wave approximation based on Saint-Venant's equation and Manning's equation. The sensitivity analysis of the model parameters exhibited that the different runoff characteristics of the tested GWWs were mainly caused by their different cross-sections. A small incision along the thalweg of the cut GWW, which resulted from storms during GWW establishment, drastically reduced its efficacy in reducing runoff from small to moderate storms.

In general the sensitivity analysis showed that runoff control in a GWW is dominated by inflow rates depending on watershed, management and rain characteristics. Also important is the hydraulic roughness in the GWW depending on vegetation and flow characteristics. For an optimized runoff control, GWW design and management should support stiff grasses and herbs and prevent submergence of the vegetation. Therefore, flat-bottomed GWWs are optimal, where the vegetation is not mowed before it could develop stiff stems and mowing height is not smaller than about $0.15 \mathrm{~m}$. In general wide, flatbottomed, long GWWs efficiently reduce runoff volume and peak discharge rate, while the slope, as fourth morphological parameter, is less important. The influence of the soil conditions was relatively marginal within the tested range. Only the sorptivity and conductivity in the rooted structured soil layer impacted runoff volume during short inflow times. A similar efficiency in runoff control can hence be expected for such GWWs on many other soils and in other landscapes as long as inflow is in a similar range. 


\section{Acknowledgements}

The scientific activities of the research network 'Forschungsverbund Agrarökosysteme München' (FAM) were financially supported by the German Federal Ministry of Education and Research (BMBF 0339370). Overhead costs of the research station of Scheyern were funded by the Bavarian State Ministry for Science, Research and Arts. The former manager of the research network, M. Kainz, is gratefully acknowledged for the idea to establish the GWW in 1993. The authors also thank B. Lechner and C. Lehmeier for their help during the runoff experiment and S. Dabney, USDA-ARS National Sedimentation Laboratory, who helped to improve the manuscript substantially during the review process.

\section{References}

Auerswald, K., Haider, J., 1996. Runoff curve numbers for small grain under German cropping conditions. J. Environ. Mgmt 47, 223-228.

Auerswald, K., Albrecht, H., Kainz, M., Pfadenhauer, J., 2000. Principles of sustainable land-use systems developed and evaluated by the Munich Research Alliance on agroecosystems (FAM). Petermanns Geograph. Mitteilungen $144,16-25$.

Barfield, B.J., Belvins, R.L., Fogle, A.W., Madison, C.E., Inamdar, S., Carey, D.I., Evangelou, V.P., 1998. Water quality impacts of natural filter strips in karst areas. Trans. ASAE 41, 371-381.

Briggs, J.A., Whitwell, T., Riley, M.B., 1999. Remediation of herbicides in runoff water from container plant nurseries utilizing grassed waterways. Weed Technol. 12, 157-164.

Carter, C.E., Parsons, D.A., 1967. Field tests on the Coshocton-type wheel runoff sampler. Trans. ASAE 10, 133-135.

Chaubey, I., Edwards, D.R., Daniel, T.C., Moore jr., P.A., Nichols, D.J., 1994. Effectiveness of vegetative filter strips in retaining surface-applied swine manure constituents. Trans. ASAE 37, 845-850.

Chaubey, I., Edwards, D.R., Daniel, T.C., Moore jr., P.A., Nichols, D.J., 1995. Effectiveness of vegetative filter strips in controlling losses of surface-applied poultry litter constituents. Trans. ASAE 38, 1687-1692.

Chow, T.L., Rees, H.W., Daigle, J.L., 1999. Effectiveness of terraces/grassed waterway systems for soil and water conservation: a field evaluation. J. Soil Water Conserv. 3, 577-583.

Dawson, L.A., Grayston, S.J., Paterson, E., 1999. Effects of grazing on the roots and rhizosphere of grasses, in: Lemaire, G. et al.
(Ed.), Grassland and Ecophysiology and Grazing Ecology. Proceedings of the International Conference, Brazil, 24-26 August 1999, Cambridge, UK, pp. 61-84.

Deletic, A., 2001. Modelling of water and sediment transport over grassed areas. J. Hydrol. 248, 168-182.

Fiener, P., Auerswald, K., 2003a. Concept and effects of a multipurpose grassed waterway. Soil Use Mgmt 19, 65-72.

Fiener, P., Auerswald, K., 2003b. Effectiveness of grassed waterways in reducing runoff and sediment delivery from agricultural watersheds. J. Environ. Qual. 32, 927-936.

Hayes, J.C., Barfield, B.J., Barnhisel, R.J., 1984. Performance of grass filter under laboratory and field conditions. Trans. ASAE 27, 1321-1331.

Hillel, D., 1998. Environmental Soil Physics. Academic Press, San Diego, CA.

Hjelmfelt, A., Wang, M., 1997. Using modelling to investigate impacts of grass waterways on water quality In: Proceedings of the 27th Congress International Association on Hydraulic Research, San Francisco, 1-15 August 1997. American Society of Civil Engineers, San Francisco, CA, pp. 1420-1425.

Jin, C.X., Römkens, M.J.M., 2001. Experimental studies of factors in determining sediment trapping in vegetative filter strips. Trans. ASAE 44, 277-288.

Jin, C.X., Römkens, M.J.M., Griffioen, F., 2000. Estimating Manning's roughness coefficient for shallow overland flow in non-submerged vegetative filter strips. Trans. ASAE 43, $1459-1466$.

Kouwen, N., 1992. Modern approach to design of grassed channels. J. Irrigat. Drain. Eng., ASCE 118, 733-743.

Lighthill, M.J., Woolhiser, D.A., 1955. On kinematic waves. 1. Flood movement in long rivers. Proc., R. Soc., Lond., Ser. A 229, 281-316.

Löpmeier, F.-J., 1994. Berechnung der Bodenfeuchte und Verdunstung mittels agrarmeteorologischer Modelle (Calculating soil moisture and evapotranspiration according to agro-meteorological models). Zeitschrift für Bewässerungswirtschaft 29, 157167 (in German).

Mockus, V., 1972. Estimation of direct runoff from storm rainfall In: SCS National Engineering Handbook. Section 4. Hydrology. USDA, Washington, DC, pp. 10.1-10.24.

Munoz-Carpena, R., Parson, J.E., Gilliam, J.W., 1993. Numerical approach to the overland flow process in vegetative filter strips. Trans. ASAE 36, 761-770.

Munoz-Carpena, R., Parsons, J.E., Gilliam, J.W., 1999. Modeling hydrology and sediment transport in vegetative filter strips. J. Hydrol. 214, 111-129.

Norris, V., 1993. The use of buffer zones to protect water quality: a review. Water Resourc. Mgmt 7, 257-272.

Ogunlela, A.O., Makanjuola, M.B., 2000. Hydraulic roughness of some African grasses. J. Agric. Eng. Res. 75, 221-224.

Overcash, M.R., Bingham, S.C., Westerman, P.W., 1981. Predicting runoff pollutant reduction in buffer zones adjacent to land treatment sites. Trans. ASAE 24, 430-435.

Philip, J.R., 1958. The theory of infiltration. 6. Effect of water depth over soil. Soil Sci. 85, 278-286.

Philip, J.R., 1969. Theory of infiltration. Adv. Hydrosci. 5, 215-296. 
Schachtschabel, P., Blume, H.P., Brümmer, G., Hartge, K.-H., Schwertmann, U., 1992. Scheffer/Schachtschabel-Lehrbuch der Bodenkunde (Scheffer/Schachtschabel-Textbook of Soil Science). Enke, Stuttgart, Germany (in German).

Schauder, H., Auerswald, K., 1992. Long-term trapping efficiency of a vegetated filter strip under agricultural use. Z. Pflanzenernähr. Bodenkd. 155, 489-492.

Scheinost, A., 1995. Pedotransfer-Funktionen zum Wasser-und Stoffhaushalt einer Bodenlandschaft. (Pedo-transfer functions for water and matter balances of a soilscape. In German, with English abstract.) $\mathrm{PhD}$ Thesis, Technische Universität München, Freising-Weihenstephan, Germany.

Scheinost, A.C., Sinowski, W., Auerswald, K., 1997. Regionalization of soil water retention curves in a highly variable soilscape. I. Developing a new pedotransfer function. Geoderma 78, 129-143.

Schmitt, T.J., Dosskey, M.G., Hoagland, K.D., 1999. Filter strip performance and processes for different vegetation, widths, and contaminats. J. Environ. Qual. 28, 1479-1489.
Schröder, R., 2000. Modellierung von Verschlämmung und Infiltration in landwirtschaftlich genutzten Einzugsgebieten. (Modelling silting and infiltration in agricultural watersheds. In German.) PhD Thesis, Universität Bonn, Bonn, Germany.

Singh, V.P., 2001. Kinematic wave modelling in water resources: a historical perspective. Hydrol. Process. 15, 671-706.

Tollner, E.W., Barfield, B.J., Haan, C.T., Kao, T.Y., 1976. Suspended sediment filtration capacity of simulated vegetation. Trans. ASAE 19, 678-682.

Tollner, E.W., Barfield, B.J., Vachirakornwatana, C., Haan, C.T., 1977. Sediment deposition patterns in simulated grass filters. Trans. ASAE 20, 940-944.

Verstraeten, G., Poesen, J., 1999. The nature of small-scale flooding, muddy floods and retention pond sedimentation in central Belgium. Geomorphology 29, 275-292.

Zillgens, B., 2001. Simulation der Abflussverminderung und des Nährstoffrückhalts in Uferstreifen. (Simulation of runoff and nutrient reduction in riparian vegetation. In German.) $\mathrm{PhD}$ Thesis, Justus-Liebig-Universität, Gießen, Germany. 